\title{
5 Die Mithridatischen Kriege. Die Krim unter der Herrschaft Roms
}

\begin{abstract}
Pantikapaion ist eine an allen Seiten in einem Umkreis von zwanzig Stadien umsiedelte Höhe, im Osten hat es einen Hafen und Schiffswerften für etwa dreißig Schiffe; es hat auch eine Burg. Es ist eine Gründung der Milesier und wurde - ebenso wie alle benachbarten Siedlungen zu beiden Seiten der Mündung des Maiotischen Sees - lange Zeit monarchisch regiert von den Machthabern Leukon, Satyros, Pairisades und ihrer Familie bis zu dem Pairisades, der Mithridates die Herrschaft übergab. Sie wurden Tyrannen genannt, obwohl sie zum größten Teil, angefangen bei Pairisades und Leukon, recht ordentlich waren; Pairisades wird sogar als ein Gott betrachtet. Denselben Namen wie er trug auch der letzte, der, unfähig gegen die Barbaren standzuhalten, die höhere Abgaben verlangten als vordem, die Herrschaft dem Mithridates Eupator übergab; seitdem ist das Königreich den Römern untertan geworden. Sein größter Teil liegt auf europäischem, ein Teil jedoch auch auf asiatischem Boden. ${ }^{1}$
\end{abstract}

So sachlich beschrieb der Geograph Strabon das Ende des unabhängigen, lange prosperierenden und von „milde[n] Oberherren“ regierten Bosporanischen Reiches und den Übergang großer Teile der Krim unter römische Herrschaft. Diese Entwicklung war nicht unbedingt abzusehen gewesen, hatte das Bosporanische Reich während der Regentschaft der Spartakoiden Leukon I. (389/8-349/8 v.Chr.) und Pairisades I. (349/8-311/10 v.Chr.) doch erhebliche Gebietsgewinne verzeichnen können, ehe Pairisades V. (ca. 150-108 v. Chr.) 108 v. Chr. sein Reich dem König von Pontos, Mithridates VI. (ca. 134 v.Chr. - 63 v. Chr.), unterstellte. Dies war für die ganze Krim ein Schritt von großer Bedeutung, wie sich alsbald zeigen sollte. Von der bereits erwähnten schweren Krise ab dem 4./3. Jahrhundert v.Chr. war nicht nur das im Osten der Halbinsel gelegene Bosporanische Reich betroffen, sondern auch die weiter westlich gelegenen griechischen Kolonien wie das bis dahin eher mit den dortigen Skythen und der Mutterstadt Herakleia Pontike verbundene Chersones oder auch Theodosia. Wirtschaftliche Probleme sowie der zunehmende Druck sarmatischer Stämme an den Grenzen verstärkten sich, wogegen man sich anfänglich mit dem Einkauf militärischer Dienstleistungen bei den Skythen und dem Ausbau der Verteidigungsanlagen behalf. Eine dauernde Entlastung brachten diese Maßnahmen allerdings nicht, so dass sich - wie von Strabon geschildert - nicht nur das Bosporanische Königreich, sondern auch Städte wie Chersones hilfesuchend an den König von Pontos, Mithridates (VI.) Eupator, wandten und damit an eine Gestalt, welche in der reichhaltigen Legenden- und Mythenwelt der Krim und des Schwarzmeerraumes ebenfalls einen

1 Strabons Geographika, Buch VII, 4. Abschnitt, § 4, zitiert nach Radt (2003), 287 f.

๑ OpenAccess. (๑) 2020 Kerstin S. Jobst, publiziert von De Gruyter. [(c))BY Dieses Werk ist lizenziert unter der Creative Commons Attribution 4.0 International. https://doi.org/10.1515/9783110520620-007 
festen Platz hat. Den Legenden nach soll dieser u.a. nach der Ermordung seines Vaters sieben Jahre in der Einöde gelebt haben, sich aus Angst vor möglichen Anschlägen durch seine Feinde durch die kontinuierliche Einnahme von Antidoten gegen jedwelche Gifte immunisiert haben, seine Mutter und den eigenen Bruder ermordet und - folgt man Plinius d. Älteren (ca. 23-79 n.Chr.) - 22 Sprachen beherrscht haben. Kein Wunder also, dass Künstler vieler Epochen (unter ihnen Jean Racine [1639-1699] oder James Joyce [1882-1941]) Bezug auf diese Gestalt nahmen. ${ }^{2}$

Mithridates galt aber auch als fähiger Heerführer, der u.a. im Jahr 108/107 v.Chr. einen Aufstand im Bosporanischen Reich niederschlagen konnte. In diesem ethnisch gemischten Gemeinwesen waren, zeittypisch, SklavInnen Teil der Ökonomie. Diesen und den zumeist freien, aber sozial weniger gut abgesicherten skythischen Unterschichten gefiel die Unterstellung unter das Königreich von Pontos nicht. Es kam 108-107 v.Chr. zu einem anfänglich erfolgreichen Aufstand unter dem Sklaven Saumakos (Savmak), wodurch Pairisades V. abgesetzt wurde und Saumakos sich statt seiner zum Herrscher ausrufen ließ. Er ließ sogar eigene Münzen prägen, wie archäologische Funde beweisen. Erst der von Mithridates entsandte pontische Feldherr Diophantes konnte die Aufständischen besiegen, worauf das Bosporanische Reich Pontos einverleibt wurde. Es ist kein Wunder, dass der sogar noch einige Jahre vor dem Aufstand des römischen Sklaven und Gladiators Spartakus gegen die römische Republik (in den siebziger Jahren v.Chr.) stattfindende Aufstand des Saumakos in den sowjetischen Geschichtswerken „besonders farbig dargestellt“ wurde, wie Helmut Neubauer in einem bereits 1960 erschienenen, aber immer noch lesenswerten Aufsatz schreibt: „Der Aufstand der bosporanischen Skythen ist die erste uns auf dem Territorium der UdSSR bekannte Bewegung geknechteter Massen gegen ihre Herren“, jubilierte beispielsweise ein von Neubauer namentlich nicht genannter sowjetischer Historiker in einem 1955 erschienenen Werk. Mithridates kam dementsprechend weniger gut bei WissenschaftlerInnen der UdSSR an, galt er doch als Exponent der Sklavenhalterökonomie. ${ }^{3}$

Mithridates herrschte über das damals mächtigste Königreich Kleinasiens, welches er dann auch noch um die schutzsuchenden von Griechinnen und Griechen bewohnten Gebiete der Krim vergrößern konnte. Damit waren seine Aspirationen aber noch nicht beendet, denn nachdem er am Schwarzen Meer Fuß gefasst hatte, versuchte er seinen Einflussbereich auf weitere kleinasiatische Gebiete auszuweiten und geriet so in Konflikt mit Rom. Die hellenischen Krim-

2 Dazu einführend Jung-Kaiser (2013).

3 Žukov (1955), 411, zitiert nach Neubauer H. (1960), 147. 
Städte wurden auf diese Weise in die drei sog. Mithridatischen Kriege (89-63 v. Chr.) hineingezogen, aus denen das Königreich Pontos als Verlierer hervorging, dessen König angesichts der Niederlage - auch dies effektvoll - Selbstmord beging. ${ }^{4}$ Nach dem endgültigen Sieg Roms 63 v. Chr. unter Pompeius (106-48 v.Chr.) wurde der westliche Teil des Königreichs in die römische Provinz Bithynia et Pontus eingegliedert, ${ }^{5}$ der Osten und das Bosporanische Reich existierten als ein von Rom abhängiger Klientelstaat weiter, wobei Pantikapaion seinen hellenischen Charakter allmählich verlor. ${ }^{6}$ Im Westen der Krim, in Chersones, entstand eine von Unterstützern Roms getragene oligarchische Republik, welche zwar die Hauptbasis römischer Herrschaft auf der Halbinsel, aber nicht als römische Provinz organisiert wurde.

Es zeigt sich schon an dieser ,Verwaltung', dass die Krim auch aus der Perspektive des Römischen Reiches eine periphere Region war, welche man nicht fest in die Reichsstruktur einbinden wollte oder konnte. Dies belegt zudem die Stationierungspolitik, denn in der Regel sollten die griechischen Kolonien sich selbst gegen kriegerische Einfälle nomadischer Eindringlinge verteidigen. Dies schloss wiederholte militärische Pazifizierungsaktionen gegen skythische Verbände zur Grenzsicherung z. B. in den 60er Jahren n. Chr. nicht aus; diese beseitigten aber die vom Norden ausgehende barbarische Gefahr nicht wirklich, auch wenn Städte wie Chersones sich wegen ihrer effektiven Befestigungen zumeist verteidigen konnten.Von länger andauernden Stationierungen römischer Truppen etwa im zweiten nachchristlichen Jahrhundert zeugen erste im 19. Jahrhundert entdeckte archäologische Funde, ${ }^{7}$ die durch neuere Grabungen bestätigt werden konnten. ${ }^{8}$ Grundsätzlich hing die Intensität der römischen Präsenz auf der Halbinsel in der letzten Hälfte des 1. und am Anfang des 2. Jahrhunderts von den allgemeinen Zuständen des römischen Ostens ab, d.h. dass die Krim auch in dieser Zeit im größeren Kontext des nördlichen Schwarzmeerraumes gesehen werden muss. Als beispielsweise gegen Ende des 1. Jahrhunderts n. Chr. die sog. Dakerkriege - benannt nach den im Karpatenraum und an der unteren Donau siedelnden Dakern begannen, zeichneten sich Folgen für die römischen Klienten immer dann ab, wenn Rom seine Truppen von der Krim abzog oder verringerte. ${ }^{9}$ Diese waren nicht

4 Vgl. dazu Højte (2009).

5 Vgl. dazu Højte (2006).

6 Rostovtzeff (1922), 155: „[I]t was no longer a real Greek city. Hellenism in Panticapaeum was perishing daily.“

7 Rostowzew (1902), 85.

8 Sarnowski u. Zubar (1996).

9 Dies ist die Bezeichnung für mehrere militärische Konflikte zwischen den sog. Dakern - vermutlich auch eher ein Sammelbegriff denn ein homogener Ethnos - und dem Römischen Reich 
grundsätzlich negativ. Dass sich der Spielraum eines Klientelstaates wie des Bosporanischen Reiches dadurch phasenweise erweiterte, sieht man etwa in der Zeit Kaiser Domitians (81-96): Die bosporanischen Herrscher Rhesuporis I. (68/993/4) und Sauromates I. (93/4-123/4) ließen Münzen mit ihren Bildnissen prägen, was nicht nur von symbolischer Relevanz war, sondern zugleich darauf hinwies, dass Rom weniger Einfluss ausüben konnte. ${ }^{10}$

Es ist wichtig, sich vor Augen zu halten, dass keinesfalls die ganze Krim unter - sei es nun nomineller oder tatsächlicher - römischer Herrschaft stand, denn im Norden der Halbinsel existierte, wie bereits erwähnt, das ebenfalls in wechselnden Beziehungen zu Rom stehende skythische Reich mit seiner Hauptstadt Neapolis. Wie schon in den Jahrhunderten davor changierte das Verhältnis zwischen den Barbaren (Skythen) und den Zivilisierten (Rom, Bosporanisches Reich) zwischen pragmatischer Kooperation, die insbesondere gegen eindringende sarmatische Stämme aus dem Norden immer wieder angezeigt war, friedlichen Phasen und offenen kriegerischen Auseinandersetzungen. Schwer wog beispielsweise die Niederlage des skythischen Reiches gegen das Bosporanische Reich unter Sauromates II. (174/175-210/211) am Ende des 2. Jahrhunderts n.Chr., von der sich die spätskythische Kultur nicht wieder erholen konnte. Der neuerliche Einzug von Barbaren im 3. Jahrhundert n. Chr. tat ein Weiteres und gipfelte in der Zerstörung Neapolis'. Die immer noch Skythen genannten Gruppen, die sich bereits in der Vergangenheit mit zahlreichen anderen Kulturen verbunden und verändert hatten, begannen endgültig als Akteur auf der Krim zu verschwinden. ${ }^{11}$ Der Grund dafür waren neue Migrationsbewegungen.

unter Domitian (81-96) und Trajan (98-117), die mit der Annexion Dakiens durch die Römer endeten. Vgl. hierzu einführend Strobel (1989).

10 Rostowzew (1902), 87.

11 Rolle u. Brenow (2006); Rolle (1980), 150. 